\title{
APLASIA CUTIS CONGENITA IN A NEWBORN SEEN AT USMAN DANFODIYO UNIVERSITY TEACHING HOSPITAL, SOKOTO, NIGERIA: CASE REPORT
}

B. Onankpa $^{1}$, A. Adamu ${ }^{2}$, R. Jega ${ }^{1}$, T. Ali ${ }^{1}$.

${ }^{1}$ Usmanu Danfodiyo University Teaching Hospital., Paediatrics, Sokoto, Nigeria. ${ }^{2}$ Usmanu Danfodiyo University Teaching Hospital, Paediatrics, Sokoto, Nigeria.

Title of Case(s)

Absence of skin tissue at birth

Background

Aplasia cutis congenital (ACC) is rare dermatological condition characterized by the absence of skin at birth. The lesion may affect the epidermis, dermis and subcutaneous tissue and can progress to involve the muscle, bone and other structures such as the dura.

The scalp is most frequently affected in approximately 90 percent of cases, but can be found in other parts of the body. It has a global incidence of 1 in 10,000 live births. This is the first to be reported from Sokoto, North western Nigeria.

Case Presentation Summary

$\mathrm{ZM}$ a female neonate delivered by a 21-year-old $\mathbf{P}_{\mathbf{3}}{ }^{+0}$ mother at a peripheral hospital. She presented at $\mathbf{1 6}$ hours of life on account of absence of skin on both lower limbs.

The neonate appeared pink, afebrile, with bilaterally symmetric absence of skin tissue on the antero-medial surface of both lower extremities extending from the knees to the plantar area of the feet. She had no scalp lesion or bullae.

Diagnosis/classification was Frieden type VII aplasia cutis congenita. Management was a multidisciplinary approach. Dressing with Eusol, povidone iodine cream and oral antibiotic (cefuroxime). Restoration of skin tissue was

noticed 2 weeks later and the baby was discharged home for follow-up.

Learning Points/Discussion

Just over 500 cases reported worldwide. No gender and racial predilection. Few cases reported in Africa with one from Jos Nigeria by Mava Y et al ${ }^{1}$. Etiology is unclear, Mutations of ribosomal GTPase BMS1 has been implicated in ACC with AD inheritance. Diagnosis is mainly clinical and treatment is both conservative and surgical. 